\title{
The episteme of happiness as ontological vertical in modern education: The Maslow answer
}

\author{
Wen Heng Fu ${ }^{a, 1, *}$, Satrianawati ${ }^{\text {a,b,2 }}$ \\ ${ }^{a}$ Harbin Normal University China \\ ${ }^{\mathrm{b}}$ Universitas Ahmad Dahlan Yogyakarta, Indonesia \\ ${ }^{1}$ wenhengfu@126.com *; ${ }^{2}$ satrianawati@pgsd.uad.ac.id \\ * corresponding author
}

ARTICLE INFO

Article history

Received 2020-04-25

Revised 2020-05-31

Accepted 2020-07-05

Keywords

The episteme of happiness

Maslow's theory

Hierarchy of needs

Modern education

\section{ABSTRACT}

The article deals with the analysis of the Maslow's ontological level answer of happiness in modern education, which forms the perspectives of development and the modern cultural core of social life. As a prerequisite for the analysis, theory Maslow about the hierarchy of needs as the ontological foundations of happiness in modern education. The methodological basis of the research made is mix-method. This research takes sixty-one participants in the survey and using interviews to strengthen data in descriptive qualitative. It established the episteme sources of Maslow's works. The results of this analysis have projected onto the current situation in modern education. This projection's ontological components are the correlation of happiness with the hierarchy of needs, a combination of theoretical understanding and get happiness, value mediation of Maslow's theory to innovate modern education. Having examined the hierarchy of needs meanings, the author shows the perspectives of the enhanced comprehension of modern education and Maslow's theory. The vertical of the paradigmaticallydifferentiated hierarchy of needs in modern education development has been considered the place of cognitive-cultural diversity. The characteristic is given of the episteme of activity to achieve happiness in the focus of research education.

This is an open access article under the CC-BY-SA license.

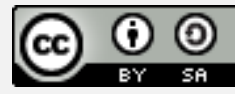

\section{Introduction}

Happiness is something all human wants in this world. In this era, happiness and money could not separate. Most money guides operate under the assumption that if you have enough information and take action, you can build wealth and be happy. But that leap from wealth to happiness is neither easy nor obvious [1]. Analyzing a book of happiness written by Nell Nodding, she explained some opinions from many philosophies. She started to explain by two ideas from Daily lama, who has known with the system of reincarnation of Living Buddha. He said, "whether one believes in a religion or not, we are all seeking something better in life the very motion of our life is toward happiness." And the second opinion from William James was an American philosopher and psychologist. The first educator to offer a psychology course in the United States (Father of American psychology) said that "The Varieties of Religious Experience this way: If we were to ask the question: "What is human life's chief concern?" one of the answers we should receive would be: "It is happiness" [2].

Two statements deal with the dimensions of value happiness because of the standards combination in ontological dimensions derived from the episteme of happiness. The very motion of our life is toward and to receive happiness, Feeling happiness is not different with fulfilling the needs of a person 
because if someone wants to be happy, she/he should have comfort in their life activities. It was coherent with Maslow theory about the hierarchy of needs.

In this paper, we do not focus that you first have to define what "the rich life" means to you, what ideas, activities, and relationships you value, and what you are striving for personally - then use the money to build that life. Too often, it works the other way around: Someone chooses a particular career to get money and then lets money define what she/he does, what she/he values, who she/he is, and what her/his life looks like [1]. Otherwise, we focus on fulfilling the needs in implementing teaching and learning in modern education. Even though, Maslow's theory explained that every human being needs the fulfilled their need. It has the same influence on peoples happiness from the bottom level until the up level. The first level is psychological needs like air, water, food, shelter, clothing, sleep, reproduction. The second level is safety, personal security, employment, resources, health, and property; the third level is love and belonging, such as friendship, family, intimacy, sense of connection. The fourth level is esteem, such .as: respect, self-esteem, status, recognition, strength, freedom. The five levels are self-actualization, such as the desire to become the most that one can be [3]. In the epistemic conception, get happiness, "ones participation is an attempt to discover what one will concerning happiness" participation is a means to understand the needs problems, but participants may not know what they desire [4]. It became a problem when the participants explained their desire is not fulfill with Maslow's theory and implementing teaching and learning during pandemic Covid19 in the modern era.

The teacher faced many problems during this pandemic. Changing their daily activities was very hard; the big question is about interdisciplinarity. It has emphasized throughout, as learners of all ages must meet the challenges of the automation economy with creativity and curiosity. As we know, not all teachers have excellent competencies, whereas in 2020 each person, especially to the teacher, needed skills that had identified, such as complex problem solving, critical thinking, creativity, people management, coordinating with others, emotional intelligence, judgment and decision making, service orientation, negotiation, and cognitive flexibility. That have no longer included in the top ten list were active listening and quality control. Cognitive flexibility and emotional intelligence were the two new skills added for 2020 to replace them because as work becomes automated, it will also become much more fluid. Employees will need to be agile and able to jump between very different types of tasks and contexts [5]. The teachers have not much experience and should face this problem without training.

In some cases, the public found much knowledge, not from the teacher, and without discussion with the teacher. As an example, the students can search for their materials on the internet. They do not have to wait for a teacher to explain. They continue searching more about the subject matter. Based on that situation, modern education is the process of shaping people into human responsiveness with changes supplemented with high intellectual and integrity to lead themselves and their lives and enlighten others understanding of the importance of advancing and develop together. Progressing the subject matter, the students develop together, and there are certain stages or sections that each person must fulfill in his or her life segment. In Maslow's theory, fill the life segment is known as the hierarchy of needs. However, everyone has a desire. Fulfill it will arrive at the highest happiness level. Sometimes happiness is a pleasure, and the realization is the fulfillment of necessity. When a person has succeeded in fulfilling her /his needs, she/he does not necessarily become satisfied because she/he is only an ordinary man who has an insatiable desire. It appears the name of the man as an economic person with a passion that cannot be satisfied. On the one hand, to meet the needs of the basics.

In A Theory of Human Motivation, in psychological Review in 1943. Maslow explained that Lowlevel needs must be met or at least adequately fulfilled first before the higher levels need become the motivating thing [6]. Besides, in this post-modern era, education has a different motivating something. Indonesia education Minister says about the motivation thing in school with three statements: first, we enter an era where the degree does not guarantee competence. Second, we enter an era where graduation does not ensure the readiness of work, and third, we enter the period where received does not provide quality [7]. These are things that the young generation must immediately realize to face life in the post-modern era. Therefore, the level of happiness in modern education that relates to the hierarchy of needs has also coherent with the student motivation things. The happiness either the teachers or the students in modern education are needed other points. It takes the ability to adapt with times and respond rapidly to changing daily life. Modern education needs to force the learners should also have adapted to the demands of the times. It is pivotal in the life of remembering every individual 
should be able to survive and create innovations in answering and through life in a harmonious rhythm. Therefore, this paper will discuss the episteme of happiness in modern education by Maslow's answer. It contains five primary needs of human that has developed according to the current situation.

\section{Method}

The methodological basis is a mix-method, such as quantitative in survey method and the descriptive qualitative doing interpretation, description, and comparison [8]. In survey data also give a question like an interview. Survey has involved 61 participants from the teacher and lecturer. They have a bachelor, master, and doctor qualifications. The survey focuses on understanding happiness in modern education and applying a qualitative method such as interpretation and description taken from theory Maslow. The comparison has been done to objects by looking at the happiness level of teachers who also become parents by emphasizing fulfilling the need in modern education implementation. It also combines data surveys and interviews online. The results have projected onto the current educational situation.

\section{Results and Discussion}

The episteme of happiness refers to the hierarchy of needs in Maslow's theory. And the ontological vertical indicates the level of fulfillment that every human wants to achieve satisfaction in their lives, coherent with modern education well-being. The starting point with the reality of our time has been characterized through metaphors of instability and ambiguity, globalization and cultural resistance, fragmentation, and transformation. A conflict and uncertain environment, along with the dissent character of thinking, is the part of modern educational communities life. Hence, the range of social and ontological problems becomes the spotlight of theoretical work, inside which the way has sought to clarify the complicated differentiated present and the indefinite future [9]. One of the essential globalization engines, the evolving phenomenon, has been the rapid development of information and communications technologies (ICTs). It has changed our lives in manifold ways, and the implications for education are enormous [10].

According to that statement, the episteme of happiness in the hierarchy of needs is also changing based on time. In the era 90, the school is the teacher center. In 2000 the school was the student center. In 2020, up to now, when the outbreak of coronavirus disease called Covid-19, the school is a digital learning and doing online school [11]. Based on the current situation, the episteme of happiness in the hierarchy of needs an answer Maslow also following the pyramid as the basis of the authority itself. The difference comes from the explanation of the ontological vertical that students need and implementing in modern education. Based on a survey conducted, all participants (teachers and lecturers) demonstrate that they are doing online learning during pandemic Covid-19. They adapt and follow the developments to be able to fulfill educational needs. They also explain that they feel discomfort if they do not perform the learning. By that way, online education that has been implemented during pandemic less could answer the anxiety they experienced, although $45.9 \%$ of teachers and lecturers use the same application in learning. Therefore, what teachers and lecturers do in online learning is analogous to Maslow's theory as a necessary need for the implementation of modern education.

Also, Maslow answers, there are five basics in the hierarchy of needs, namely: physiological needs, a need for safety, a need for compassion and compassion, the need for appreciation and the need for self-actualization. Maslow hypothesizes that after individuals satisfy the demand at the very bottom level, the individual will meet the requirements at the next level. If the basic needs are not satisfied at the highest level, then the individual can return at a previous level of need. According to Maslow, the expansion of these needs has driven by two strengths, deficiency motivation and growth motivation. The lack of motivation aims to address the problem of social tension due to the various deficiencies. While growth and thrive, motivation has based on the capacity of every human being. The position is innate to every human being. Conversely, in modern education analysis, the hierarchy of needs also follows era development. This era is the millennial generation era with high risk and dynamic. 


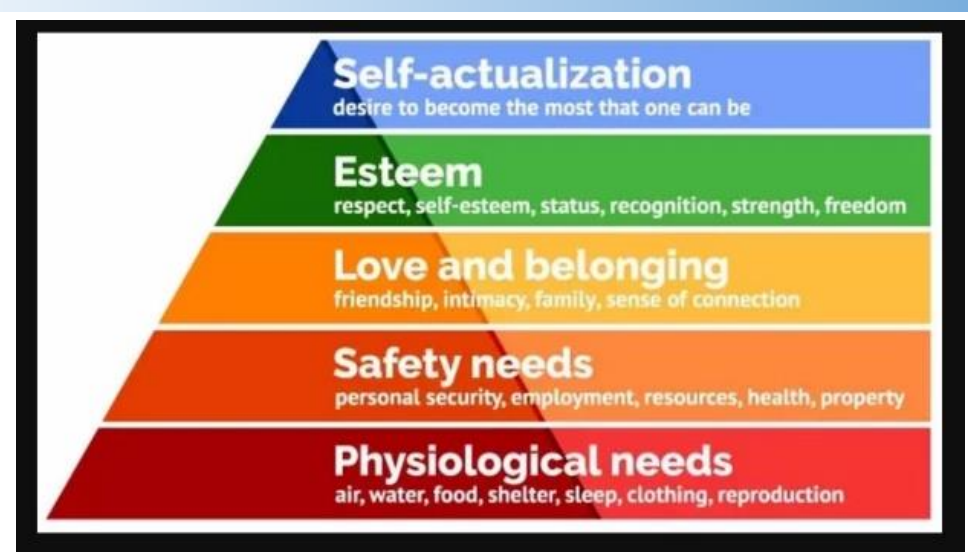

Fig. 1. The Pyramid of Hierarchy of Needs [12].

Notably, the high-risk dynamic in the primary component of teaching and learning is teacher, student, and material. Teachers and students are essential components of the teaching and learning process. It has seen in Fig 2.

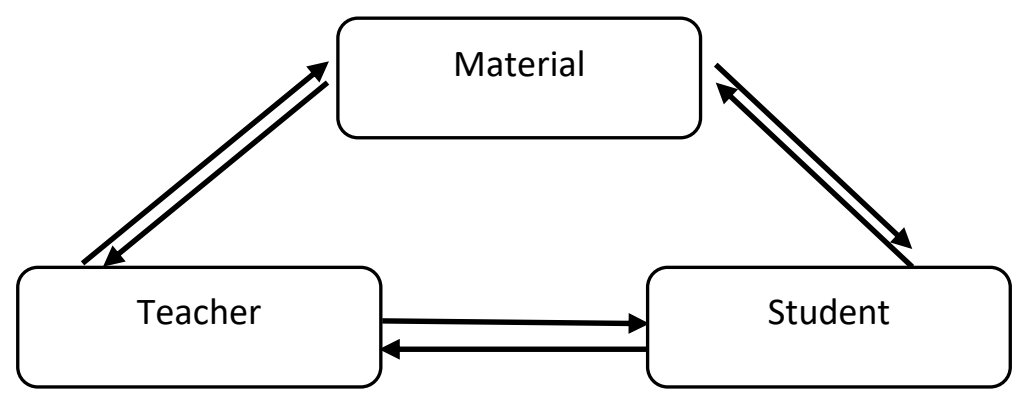

Fig. 2. Pivotal Component Teaching and Learning

The process is not as easy as a picture. We look at today's generations (the students) have faced the challenge that admission at school students only get the theory without being ready to work in the field. Focusing on two substantial professional development for teachers in evaluation produced mixed results during a pandemic when teaching and learning method change. First, while there was undoubtedly more, and certainly better communication in the field, there was also an enormous chatter. Second, while progress has been made in improving the training and certification of evaluators to ensure that institutions obtain services from qualified persons. Finally, despite a growing search for appropriate methods, increased communication and understanding among the leading methodologists, and the development of new techniques, the actual practice of evaluation changed very little in the vast majority of settings [13].

Meanwhile, teachers should change the learning system to be practical by utilizing technology. For example, by using a mobile phone in the learning System, the teacher encourages the students to use the program from their mobile phones to make innovations of any objects in their surroundings. Based on the example, the hierarchy of needs in Maslow's theory has also developed following the actual situation. Thus, the happiness education modern and the hierarchy of needs have concepts see Fig 1, such as physiological needs in modern education, Safety/Security Needs in modern education, Social Needs in modern education, esteem Needs in modern education, and Self-actualization Needs in modern education.

\subsection{Physiological Needs in modern education}

The physiological need for modern education has complicated. The key to understanding physiological needs during the current school is acknowledging the teacher's necessity and the students. Both of them have the highest dependent on each other. The survey showed the teacher spend their own money to get happiness to fulfill their physiological needs. Whereas, the physiological needs in modern education differ from other requirements. These two aspects should understand to get 
satisfaction in that. First, physiological necessity is the only need that can be fully satisfied or minimally overcome. Secondly, the distinctive physiological needs are the nature of his repatriation.

Many things should be available to students while doing learning activities. In physiological needs, there are three things to achieve happiness in modern education. The first things for students must have like a computer, laptop, android, and available access. Without one of three components of that pivotal things, the student could not become the modern education student. Infield, we established that $78,7 \%$ of respondents often spend their money buying data packets for doing teaching and learning and their use of their facilities.

The second thing has learning resources that be able to access. For example, it has facilitated in accessing official websites and specific journals. The provision of trusted learning resources can be essential happiness in the implementation of education programs in the modern era without exception. Now, when the Covid-19 outbreak, some journals open free access. That is not giving happiness for a student who was learning during the pandemic; otherwise, the limited time for free access journals when the Covid-19 outbreak can slowly, softly, and surely kill somebody. The survey showed $13,1 \%$ the teacher often used the website for access data, 32,8\% usually, 24,6\% sometimes, $23 \%$ seldom, and $19,6 \%$ never access the journal. In Webinar about education transformation facing Disruption, Hamid, as a Director of Education in Indonesia, said not all places in Indonesia available internet. If they make the internet open, it is not stable [14].

The reality, they never access because they have a terrible signal, lack of data packet, and they do not know how to access it. This reason different from the teacher who always has access and continues to collect information in the journal because they should fulfill the references to explain the subject matter to their students in an online class. Besides, they said that sometimes they have trouble in access because of limited time. Whereas to get happiness, learning access means no limited time, and both the teacher and the students can learning everything in a virtual process. Somehow the physiological needs should cover the students in learning because many learning resources can undoubtedly improve the quality of students as the millennial generation. Besides, it can motivate them to learn more. So that they are rich with information, and they can solve problems professionally. They also can innovate some materials and create new things.

After the students fulfill the second thing, the third component has an account. People can feel good enough in activities that run by having a personal account because modern education is an education with a system that using technology in learning, ranging from data search or learning materials, the innovation of learning materials, delivery of learning materials, evaluation of learning outcomes, retention of understanding students, and the creation of products for an inheritance to the next generations. For someone with an account, he or she can do anything from their account. The repatriation of physiological needs means a personal account can have reestablished when it comes to having a lot of followers or materials to be examined. It also can use for doing evaluations by themselves about what has been understood. Because every person has been studying a lot of content, while the capacity to remember matter is limited.

\subsection{Safety/Security Needs in modern education}

The specific meaning of the episteme of happiness in modern education is about safety or security Needs. Security is a top priority in every condition. Maslow's hierarchy of needs uses an ecological approach to examining the needs of individuals, by highlighting multiple individuals (i.e., esteem and locus of control), family (i.e., family SES, family stressors, and connection between family members), and community (i.e., safe environments) characteristics and how they build on and overlap with each other [15].

In modern education, security needs have fulfilled after a sufficient physiological need. These security requirements include physical security, stability, dependency, protection, and freedom from threatening power. In the context of modern education, to achieve the necessary happiness security needs, the students are safe from the environment, data hackers, data loss, etc. The survey showed $68,9 \%$ the teacher do not realize about data secure whereas they also understand passed the process about five steps to keep your data safe, has explained by Samantha, such as: (1) use strong passwords: make passwords at least eight characters, use a combination of letters and numbers, and use a different password for every site you access; (2) use virus protection: you should also use a firewall when 
accessing the internet at home or away from a corporate office; (3) Be cautious when providing information: never give your password to someone you do not know, and never send password information over email; (4) keep your computer safe: lock your computer when you are away from it for any amount of time; (5) back up information: no one enjoys losing work, always back up data to a secure server, avoid saving work on your computer desktop or other local folders [16]. The teacher abandoned points three, four, and five because some do not understand, a side-effect of age, and the weak of understanding. And only 31,1\% of the teacher implementing Samantha suggestion. Based on that data, the teachers episteme of happiness in safety and security showed a lack of intention and awareness.

More explained, safety from psychic security needs that threaten psychiatric conditions such as not being taunted, not humbled, not stressed, etc. Also, the need for a sense of safety differs from physiological needs because this need cannot satisfy in total. Humans can never protect from threats of terror, fire, flood, or other people's harmful behaviors around it. According to Maslow, in the context of modern education, unsafe people will behave just like children who are not safe. They will act as if they were always in a state of great danger. A non-safe person needs excessive regularity and stability and will strive to avoid strangely, and something that they don't want.

\subsection{Social Needs in Modern Education}

The third happiness to fulfill in modern education is social needs. The meaning of the episteme of happiness social needs appears when physiological needs and safety needs have fulfilled. This need relates to love, compassion, and a sense of belonging. [6] These needs include encouragement to be needed by others to be regarded as a citizen of his social community. The social need contains their friends (student-student), student-teacher, and students-parents. The social need has a significant impact on creating efficient learning. Efficient learning should have based on a close partnership with parents and local communities. Important goals must have set to meet the multiple learning needs of young people. A flexible education system covering both public and private sectors should be available [17].

The survey showed that $90,2 \%$ of the teacher active online learning during a pandemic because of their need to keep interaction between their friends (student-student), student-teacher, and studentsparents and 9,8\% the teacher explained also want to do online learning but the condition not support the process. Comparing the achievement of the teacher, who was doing and not doing, the episteme of happiness in social needs is essential within implementing education in the modern era. In modern education, the process of learning and teaching teachers and students who have the technology to accommodate the message in the form of both students and teachers' expressions. For example, when learning a child has not understood the material submitted, then the tone of the menu option to be able to click and be known by the teacher about incomprehension students. Through the menu choice of flavors or expressions of expression that exist, then the teacher, the parents, and the students will be an excellent social relationship, they showed about the existence of love and caring. The survey showed that $90,2 \%$ of the teacher as parents contact their children's teachers to ask about the task of their child. Even though $70,5 \%$ of the teacher as parents also ever trouble their time when accompanying their child learning online.

In sum, teachers, parents, and students' relationships in the context of modern education are concerned with healthy relationships and responsible for their duties. Students who are accustomed to fulfilling or working on their duties will have a high conviction that his teacher loves him. Conversely, teachers who always motivate the advancement of learning students have the confidence that his success as a teacher. Teachers consider students concerned with the lessons given, and students feel loved by teachers when given an understanding of science. The students and teacher also being teamwork. Teamwork is a fertile context in which to fulfill these needs because how it connects people with different tangible (e.g., written report, product design) and intangible (e.g., an idea for process improvement) products of work. When people create something with others, they can experience the output of their work as an extension of the group as "ours." [18]. Indirectly, their teamwork will establish a positive effect on self-esteem. The mechanisms of work contingent both time-separated and full-time have impacts well-being at work and outside of work. Also, both autonomous and internally controlled work motivations and the beneficial effects outweighed its harm-full effects on job satisfaction and neutralized its harmful consequences for all other outcomes [19]. It means the 
social need of Maslow's theory for getting happiness in modern education also encourages every student to collaborate in their work.

\subsection{Esteem Needs in Modern Education}

The modern education of esteem needs is crucial as it relates to the ego that is owned by students to be able to excel and possess prestige. Esteem needs are the basis for human desire. This need gives a considerable and tangible impact in changing the patterns of human behavior in everyday life. Because each person wants to be accepted and valued by others, besides, the realization of the esteem needs can provide a direct effect on the awards received by the students whether the student received an excellent prestige from the teacher or not. On the one hand, students who get high esteem needs in modern education tend to innovate to create new things. It means they become critical thinking also the tangible impact of learning environments conducive to reflection and argumentation through innovation. The abilities have developed through direct instruction. The dispositions have better thought of as "habits of mind," and their development requires long-term participation in learning environments conducive to reflection and argumentation [20].

Meanwhile, the teacher gives a reward to the students for what they have done. It has a positive effect on student prestige. Otherwise, the survey showed 68,9\% of teachers got awards from the other (in their social environment, their friends, their relatives, their child) when they were actively implementing online teaching in modern education. It is also increasing their self-prestige. The survey showed $82 \%$ teacher feel their prestige become higher than before. Reward also took $88,5 \%$ of teachers to give positive responses to their social life. $93,5 \%$ of the teacher also appreciate the others who act in implementing online learning in modern education.

The esteem needs in modern education also encourage the student to have a social reproduction process in school to deal with the world of work. Ambition determines the students for future positions in the social space. It means what students do to get happiness in esteem needs comparisons had made between the notions of education and working life transmitted by different course programs and the opinions found in various sectors and levels of working life [21]. Rice said having knowledge, awareness, and skills in cultural competency, service delivery professionals are better prepared to do their jobs [22]. Therefore, esteem needs naturally come when the students feel good about themself. They prefer to have others tell what they have done in a good job. To get happiness in esteem needs, the students seek fame and glory. They have confidence in their life despite others not knowing about their successes. Notably, every person has different esteem needs because it depends on their condition. Their self-esteem might have based on what others say about "a good job," they have done, or what they say about themself. Having positive feelings about themself is necessary for their overall emotional health and well-being. Especially in modern education each person without properly meeting esteem needs, they are filled with feelings of inferiority and negativity regarding their lives. Thus, getting happiness in modern education, the students need the teacher, and others respect their job.

\subsection{Self-actualization Needs in modern education}

The last level of the basic necessity of Maslow in happiness is self-actualization. Self-actualization is different from self-esteem and self-realization. Self-actualization is the tendency to fulfill one's potential. Self-esteem is the overall subjective evaluation of one's value [23]. Self-realization is about discovering who we indeed are outside of the ego's patterns and habits. It involves letting go of attachments that keep us stuck in old unhelpful cycles, and realizing the power of the mind to re-train and re-direct itself [24]. In an online interview, the teacher explained that actualization realizes the real condition in their activity during pandemic Covid-19 in the modern era. When they post an actual status about education in that situation, the teacher understands, that they were doing what Rene Descartes said, "I think therefore I am" [25]. Besides, ecological frameworks are valuable for understanding the development and growth of happiness in self-actualization will remove the intersection between individuals, families, and communities. Happiness actualized itself has been done by proving and showing his ability to others both in the form of ideas, products, etc. The survey revealed the self-actualization factor influenced by motivation from internal and external individuals and the teacher's leisure. Surely internal and external motivation is the luxurious complex of 
discussion. Focusing self-actualization in this paper means the publication and sharing what teachers have done in their job, like the research, their article, etc. A motivation factor has positively correlated to work engagement [26]. When the teachers have leisure, they spend their time to actualize their update condition. More generally, leisure not only produces detachment from work, but it can also help individuals detach from life pressures and create more positive cognitions and emotions through recovery [27].

The survey showed $32,8 \%$ of teachers never share their product on social media before it becomes a book, $26,2 \%$ of teachers seldom sharing their product, $27,9 \%$ of teachers sometimes share their products on social media. Only 13,1 teacher always share their product on social media. When the teacher was sharing their idea. Likely, the teacher realizes that actualization is a way to improve and doing transformation with the advent of the "knowledge society" and the "knowledge-based economy," this measure of literacy skills is particularly relevant [28]. The teachers also realize when they were sharing their product, it will impact their economy because the mind society change from knowledge content to research content.

Therefore, in modern education demands, one develops as much as possible all its potential through work in the field of knowledge that can benefit many people. Sometimes the need for actualization in modern education becomes unbalanced because the potential and desire are not the same. Maslow represents this need as a desire to become increasingly self-righteous, becoming anything according to his ability. It is effected by educational aspiration in each people. Educational goals assessed by asking: "Thinking about your schooling, what level of education do you think you will obtain?" The educational attainment levels ranged from 1 (less than high school graduation) to 9 (beyond the first university degree, master's or higher). This type of indicator has used in the National Educational Longitudinal Study of 1988 and other studies. In measuring the level of aspired or expected education, a single indicator has been considered reliable [29]. For example, in actualization, a musician must make music, an artist must paint, a poet must write if he is ultimately at peace with himself. What a man can be, he must be. This need we may call self-actualization. It refers to man's desire for selffulfillment, namely to the tendency for him to become actually in what he is potentially: to become everything that one is capable of becoming [30].

Nevertheless, modern education requires the implementation of education through each student's account to continue upgrading itself and updating every science and information related to the field they are learning. So indirectly, students, while learning, can also actualize themselves. However, two things are going on in the area: first, students realize themselves but do not know what has written. Secondly, students actualize themselves according to what he knows.

\section{Conclusion}

The ontological horizon of happiness in modern education can comprehend through fulfilling the needs of humans in daily life while involving themselves in studying. Happiness is considered the fulfillment of obligations into reality and becomes a crucial, primarily life. In this situation, humans' satisfaction is an answer to physiological needs, safety/security needs, social needs, esteem needs, and self-actualization. The way humans achieve their needs in practicing will involve other people and represent what other people want. Indirectly, the needs of human happiness have a challenge and needing the unique skill to create it. Because every person should create their joy in life, and at the same time, collaboration and building relationships between people will penetrate any experience and become absolute.

Based on the analysis, the episteme of happiness (hierarchy of needs), determine the modern education principles development have explicated. The area of the multi-sectoral system of hierarchy of needs in modern education, which is becoming today a recipient and bearer of these principles, is described. The methodological basis of the research made is the hermeneutic study of the ancient sources - the works by Maslow. Therefore changing the concept hierarchy of needs based on what the millennial generation face today becomes an obligation for the government to develop education. By the system, the ministry of education has the authority to instruct all teachers and all teenagers in school to innovate the pedagogy process. The teaching and learning process should provide orientation in applicants of the students for future life. That is what modern education purpose. 


\section{Acknowledgment}

This research collaborates between Universitas Ahmad Dahlan Yogyakarta, Indonesia, and Harbin Normal University, China. We express the deepest gratitude for all those who have helped complete this paper.

\section{References}

[1] L. Rowley, Money and Happiness. New Jersey, Canada: John Wiley, 2005, available at: Google Scholar.

[2] N. Noddings, Happiness and Education. Cambridge, New York: Cambridge University Press, 2003, available at: Google Scholar.

[3] S. M. Leod, "Maslow' s Hierarchy of Needs," Highgate Counselling Centre, 2013, available at: highgatecounselling.org.uk.

[4] Mette Arleth, GIS for Sustainable Development. London: CRC Press, 2006, available at: Google Books.

[5] N. W. Gleason, Higher Education In The Era of The Fourth Industrial Revolution, First. Singapore: Palgrave Macmillan, 2018, doi: 20.500.12657/23279.

[6] C. D. Green and A. H. Maslow, "Classics in the History of Psychology A Theory of Human Motivation," 2000, available at: Google Scholar.

[7] N. Makarim, “Analyse Problem Education (Minister of Education in Indonesia)," Jakarta, 2019.

[8] N. K. D. Y. S. Lincoln, Qualitative Research, Third. London, England: Sage Publications, 2005, available at: Google Books.

[9] A. Karpov, "The Ancient Episteme of Activity as Ontological Horizon of Modern Education Development," vol. 214, no. June, pp. 448-456, 2015, doi: 10.1016/j.sbspro.2015.11.720.

[10] Ping Lim C., Khine M. (2009) Connecting Schools to their Communities: The South-East Asian Experience. In: Gibbs D., Zajda J. (eds) Comparative Information Technology. Globalisation, Comparative Education and Policy Research, vol 4. Springer, Dordrecht, doi: 10.1007/978-1-4020-9426$2 \_6$.

[11] W. Satrianawati \& Heng, "Education for Sustainable Development ( ESD ) in Indonesia : A Conceptual Framework," vol. 1, no. 1, pp. 42-49, 2019, doi: 10.31763/ijele.v1i1.33.

[12] Wikipedia, "Maslow's hierarchy of needs," 2019. [Online]. Available: https://en.wikipedia.org/wiki/Maslow\%27s_hierarchy_of_needs, available at: Wikipedia.

[13] Daniel J. Reschly (1988) Special Education Reform: School Psychology Revolution, School Psychology Review, 17:3, 459-475, DOI: 10.1080/02796015.1988.12085362.

[14] Hamid Muhammad, Webinar Theme "Education Transformation Face Disruption," vol. Zoom id: 9, no. 7 Mei. Yogyakarta, 2020, p. First speaker.

[15] A. Crandall et al., "Maslow' s Hierarchy of Needs as a Framework for Understanding Adolescent Depressive Symptoms Over Time," J. Child Fam. Stud., vol. 14, no. Child and Family, 2019, doi: 10.1007/s10826-019-01577-4.

[16] S. Orr, "The Importance of Security," 2020. [Online]. Available: https://www.wordfly.com/theimportance-of-security/.

[17] E. R. Vasilyeva, "Influence of Globalization on Modern Education," vol. 113, no. Fred 2019, pp. 75-78, 2020, doi: 10.2991/fred-19.2020.17.

[18] A. P. Giordano, D. Patient, A. M. Passos, and F. Sguera, "Antecedents and Consequences of Collective Psychological Ownership: The Validation of a Conceptual Model," J. Organ. Behav., vol. 4, no. 1, pp. 32-49, 2020, doi: 10.1002/job.2418.

[19] L. Kuykendall, L. Craig, and L. Tay, "Work - contingent self - esteem : A boon or bane for worker well - being ?," J. Organ. Behav., vol. 4, no. 1, pp. 1-16, 2020, doi: 10.1002/job.2408. 
[20] E. Aizikovitsh-udi and D. Cheng, "Developing Critical Thinking Skills from Dispositions to Abilities : Mathematics Education from Early Childhood to High," Creat. Educ., vol. 6, no. March, pp. 455-462, 2015, doi: 10.4236/ce.2015.64045.

[21] C. U. Frykholm and R. Nitzler, "Working life as pedagogical discourse : empirical studies of vocational and career education based on theories of Bourdieu and Bernstein Working life as pedagogical discourse : empirical studies of vocational and career education based on theories of Bour," J. Curric. Stud., vol. 25, no. 5, pp. 37-41, 2014, doi: 10.1080/0022027930250503.

[22] M. F. Rice, “A post-modern cultural competency framework for public administration and public service delivery," Int. J. Public Sect. Manag., vol. 20, no. 7, pp. 622-637, 2007, doi: 10.1108/09513550710823524.

[23] G. Brown, "Difference Between Self-Actualization and Self-Esteem," http://www.differencebetween.net/language/difference-between-self-actualization-and-self-esteem/, 2020. [Online]. Available: http://www.differencebetween.net/language/difference-between-selfactualization-and-self-esteem/.

[24] D. Kovacevic, "Self Realization vs Self-Actualization - Part 1: Maslow's Hierarchy," Ego Science. [Online]. Available: https://egoscience.com/self-realization-vs-self-actualization-part-1/.

[25] The-Philosophy.com, "Descartes: I think therefore I am," The Philosophy, 2020. [Online]. Available: https://www.the-philosophy.com/descartes-i-think-therefore-i-am.

[26] N. Gillet, E. Fouquereau, and R. J. Vallerand, “The Role of Workers' Motivational Profiles in Affective and Organizational Factors,” J. Happiness Stud., 2017, doi: 10.1007/s10902-017-9867-9.

[27] D. B. Newman, L. Tay, and E. Diener, "Leisure and Subjective Well-Being : A Model of Psychological Mechanisms as Mediating Factors," J. Happiness Study, vol. 16 April, pp. 1-24, 2013, doi: 10.1007/s10902-013-9435-X.

[28] S. Vézina and A. Bélanger, "Are large surveys of adult literacy skills as comparable over time as we think?," Large-Scale Assessments Educ., vol. 8, no. 1, pp. 1-23, 2020, doi: 10.1186/s40536-020-000803.

[29] R. Garg, S. Melanson, and E. Levin, "Educational Aspirations of Male and Female Adolescents from Single-Parent and Two Biological Parent Families: A Comparison of Influential Factors," J. Youth Adolesc., vol. 36, pp. 1010-1023, 2007, doi: 10.1007/s10964-006-9137-3.

[30] A. H. Maslow, With, and D. C. S. and G. Heil, Maslow on Management, 1st ed. San Mateo, California: Wiley, 1998, available at: Google Scholar. 